\title{
Who Is the Successful Negotiator? Correlates of University Students' Concepts of Effective Negotiation-Based Behaviour
}

\author{
Eleni Makri \\ Unicaf University
}

In loving memory of my parents,
doctor Georgios Makris and
teacher Georgia Tsiotou-Makri

\begin{abstract}
Research in negotiation and conflict management continuum has been triggered by challenges in defining the most successfully established negotiation globally. Accepting no definite directives for win-win perspective across diverse social and cultural contexts, this study builds on analyzing negotiation and conflict resolution attitudes and skills explored in academic environment. We report Greek university students' negotiation practice as part of a pilot study performed at a private university during the academic years 2019/2020. 116 college students took part in the case study designed to appraise their negotiation and conflict management behaviour in terms of assertiveness, cooperation, communication, compromise/bargaining and conflict resolution strategies. State/region origin did not affect participants' negotiation and conflict resolution experience, while work status did influence students' conflict management settlement post-evaluation. The negotiation continuum outcomes indicated are discussed along theoretical and practical implications and streams for further research in tandem with international negotiationassociated instruction and experience.
\end{abstract}

\section{Introduction}

"Sometimes one pays most for the things one gets for nothing" Albert Einstein [1 p. 13]

Negotiation is a social interacting process by which two or more parties (agents) make decisions, allocate resources, or resolve disagreements. It reflects differing preferences between partners and involves decision making and influence one another while working together to accomplish a satisfactory agreed outcome. This social procedure may take place between both human to human and human to advanced information and communication technology (ICT) applications (e.g. intelligent tutoring systems, embodied conversational agents, chat bots, robots, serious games, etc.) evident in various individual (health and well-being), social (entertainment), academic (education) and business (training) settings worldwide [2][3]. Negotiation is also a pervasive activity and complex phenomenon explored within multidisciplinary research fields. Relevant research postulates that challenges, conflicts or disagreements between individuals in a given social context (e.g. intergroup, interpersonal, organizational, international) may be addressed and resolved either with more integrative and collaborative (win-win) or more competitive, antagonistic and dominating (win-lose) strategies [4][5]. According to [6], choosing the best way out of challenge, conflict (or disagreement) to reach a consensus (integration), collaborate and (or) compromise, means that negotiating partners tend to settle their differences equally without one side gaining advantage over the other. Adversely, when accommodating (or obliging), avoiding and (or) dominating (forcing) during interaction, one negotiating partner either places more value on his own interest at the expense of the others or puts way its own objectives in favour of the other party involved. Building integrative favourable negotiation-related attitudes and skills is important across all generations. However, diverse academic and business curricula and related activities worldwide are designed to instigate younger individuals and millennials, in particular, with the critical negotiation-associated attitudes, values, knowledge and skills to proactively help or strengthen the successful exercise of and influence on present and future positive real-life negotiation outcomes [7][8][9]. The aforementioned deployment of differing negotiation-associated modules and programmes nationally and internationally, tend to form on one hand a diverse in negotiation-related attitudes and skills framework, but on the other, inconsistent evidence as regards the nature and features of negotiation and conflict management continuum among young adults [10]. In that respect, therefore, additional research in disentangling the negotiation and conflict resolution patterns among 
different populations across various educational and cultural contexts to inform the design and execution of negotiation and conflict management face to face and (or) rich technological solutions' instruction existed for feedback and additional improvements, is needed. In this context, the present paper aims to report on the results of a larger pilot study executed at private tertiary education institution in Greece, exploring students' negotiation and conflict resolution attitudes and skills in terms of selfconfidence, cooperation, communication, compromise (bargaining) and conflict resolution strategies during the academic years 2019-2020. The survey was designed and conducted in 116 college students attending a private university in Greece in order to explore the nature and level of their negotiation continuum as means to facilitate successful conflict management and negotiation engagement and vice versa. According to the aforementioned reasoning and rationale, therefore, the research question that adheres to the scope of the present study is the following:

- Are there any differences in the perceptions of negotiation-related and conflict resolution strategies employed by university students based on gender and working status?

- Are there any differences in the perceptions of negotiation and conflict resolution-continuum related strategies employed by university students based on state (region) origin and working status?

The remainder of the present paper is organized as follows. Section 2 elaborates on a summary review about negotiation and conflict resolution approaches research findings across negotiationrelated continuum in younger and older organizational and college education populations and settings. Section 3 illustrates the study methodology and the empirical evidence analysis. Section 4 summarizes the results, their implications in terms of negotiation-associated taxonomy and practice and Section 5 concludes this paper with future streams of cross-cultural advanced solutions negotiation and conflict resolution continuum research across diverse educational and business contexts alike.

\section{Literature review}

Anytime two or more interdependent negotiating partners (or agents) interact to work out the terms of their association-whether they represent their own interests, their organizations' objectives, their governments' tokens or their family's desires-they are negotiating. To reach a mutually beneficial agreement. This consensus based on increased joint gains tends to form satisfaction, strengthen deal implementation and rapport between involved parties
[11]. However, neither a definite framework of conflict resolution continuum has been reached yet, nor absolutely secure relationships between ethical negotiation-associated attitudes and variables have been revealed [12]. As such, advancing research in university context, in specific, by inserting conflict resolution exploration across millennial education cohort culture and learning experience, might disentangle further the inconsistent evidence on negotiation-associated attitudes and skills, as briefly illustrated below.

Park and Antonioni [13] elaborate on their study executed on 384 organizational behaviour undergraduate students in USA. They asked the participants to indicate which of the following 4 conflict resolution approaches they used recalling a conflict incident with their roommate (friend) during last 3 months (i.e. competition, accommodation, collaboration and/or avoidance). Although the reflected frame or kind of interaction was perceived to be different between roommates and friends, yet, the students used mostly competition, accommodation and collaboration strategies to resolve their conflict condition both with their roommates and friends, respectively. Certain personality characteristics were indicated to relate more with specific strategies. For example, agreeableness and extroversion were found to be related both with collaboration approach, but the first one was linked to a greater extent with the friends' conflict resolution setting. Students perceived as more neurotic tended to use more the collaboration conflict resolution strategy in relation to their peers perceived as more emotionally stable. The more extraverted students did report the more often use of competition in comparison to avoidance strategy. In all conflict resolution cases, it was indicated that both the roommate/friends' collaboration, competition and avoidance approaches were favourably related to the students' collaboration competition and avoidance strategies, accordingly. Agreeableness was indicated to interact with roommate and friends' usage of collaboration approach to predict own employment of collaboration strategy, but its' influence was lowered when the roommates and friends employed more collaboration. Openess was reported to interact with roommate and friends' application of competition and with their use of accommodation mode to predict students' use of competition. However, it was reported to be unfavourably related to the students' application of competition, when the roommates and friends did not score high in competing and positively related to the corresponding students' use of competition, when the roommates and friends indicated higher scores in competing, respectively. In cases where the roommates and friends reported low usage of accommodation, students' openness was favourably connected to students' using competition. 
When the roommates and friends employed accommodation at a higher level, the student's openness was negatively associated with their use of competing when the roommate/friend scored high in the use of accommodation.

Ford-Wood and Bell [14] report on their conflict resolution research involving 288 introductory psychology students from diverse cultural and gender background (i.e. $86 \%$ Caucasians, $12.2 \%$ either African-American or American-Indian or Asian-American or Latino, $36.5 \%$ males and $63.2 \%$ females) in the USA. Their findings indicated that agreeableness was found to predict collaboration approach, with extraversion related to avoidance and both agreeableness and extroversion linked to accommodation and competition, respectively. The above results are claimed by the authors as a) consistent with those indicated by [15] in that individuals adopting competition tend to be characterized by decreased need for affiliation and increased need for dominance, while those employing accommodation seem to reflect the opposite pattern (i.e. increased need for affiliation and lowered need for dominance, accordingly) and b) potentially attributed further to the fact that avoidance or collaboration may be affected more by contextual factors than personality traits.

Kiralp, Dincyürek and Beidoğlu [16] elaborate on their conflict resolution survey conducted among 200 students from various university departments in North Cyprus. Compromise was indicated as the most frequently adopted approach by the participants in interacting with their overall social networks (i.e. friends, family members), collaboration and compromise were the mostly used strategies with friends, avoidance with family and forcing framework with friends, respectively. Consistent with the above findings, Dinçyürek [17] in a similar research in North Cyprus engaging college students, indicated that avoidance and compromise approaches were employed towards family members and particularly father, while forcing and accommodation strategies were used towards friends.

Dialoke and Ogbu [18] in their survey involving 124 employees of diverse administrative level across 10 oil industries regarding their level of agreement with using relevant conflict resolution strategies, indicated the following: a) 58\% of employees strongly agreed, $31 \%$ agreed, $6 \%$ disagreed, $2 \%$ strongly disagreed and $3 \%$ were undecided whether to use integrative (i.e. problem-solving) conflict resolution and b) $87 \%$ of participants strongly agreed, $8 \%$ agreed, $0 \%$ disagreed, $2 \%$ strongly disagreed and $3 \%$ were undecided whether to use compromise conflict management. Integrative (i.e. problem-solving) and compromise conflict resolution were favourably related to employees' commitment with their organization, supporting the argument that when 2 competitive sides agree to deal with their differences on equal terms without one taking advantage the other, employees' loyalty and positive orientation towards achieving organizational objectives, is likely to be subsequently increased. Bouwman et al. [19] describe their survey on Dutch graduate and undergraduate public and business administration students participating in an 8 sessions lab experiment exercising a repeated negotiation public goods game given a low-stakes negotiation task (i.e. tracing the offers and outcomes of individual negotiators) and able to choose between competitive and cooperative strategy, with the former bearing higher scores among business and the latter indicating increased scores among the public administration peers, respectively.

Taylor, Mesmer-Magnus and Burns [20] report on their 2 wave-cohort study involving graduate working students in the USA. The participants were 24-54 years old, with $37.8 \%$ of them being females and $52 \%$ males, respectively. They were instructed to exercise a role-play negotiation simulation in class as part of their negotiation training module and answer a post-simulation conflict management questionnaire assessing a) their own primary conflict resolution strategies used (i.e. competition, accommodation, compromise, problem-solving and avoidance) and b) their negotiating counterparts resolution approaches employed. During the final class of the semester, they were asked to report whether the instructed module intervention was helpful in developing their negotiation-building attitudes and skills (cohort 1). 618 months after the negotiation training intervention, they were asked to report whether they used such conflict resolution approaches as primary in actual situations, to indicate them in more details and how they assess themselves as negotiators, before-andafter negotiation training intervention scheme (cohort 2). Cohort 1 students indicated they felt they had improved their individual negotiating attitudes and skills due to the training module and $61 \%$ of them reporting they would have rated themselves as average or below-average negotiators during pretraining module. At the end of the module, $94 \%$ of the participants rated themselves as above-average negotiating partners. $45 \%$ of the students indicated particular favourable negotiation outcomes accomplished in actual negotiation situations (i.e. interpersonal, work, financial). Cohort 2 participants reported that they would have rated themselves as average or below average during pre-negotiation training course $(60 \%)$, but adopted instructed negotiation strategies in their post-training real-life conditions. After training course intervention, they indicated significant increase in use of compromise and collaboration as primary strategies and corresponding decrease in competition approach, respectively. 6-18 months post-negotiation training intervention, students did seem to employ predominantly compromise and (or) collaboration 
over the less successful competitive negotiation approach.

In the course of aforementioned negotiationconflict resolution review findings, diverse degree university students from certain USA states appeared to use competition, accommodation and collaboration conflict management strategies with a) agreeableness and extroversion personality traits related more with collaboration and competition, with b) their business degree peers in the Netherlands using more competition and c) their public administration counterparts cooperation resolution approach, respectively [13][14]. Different curricula college students from North Cyprus and South Eastern public university in the USA seemed to a) strongly agree with compromise/bargaining and avoidance as mostly used approaches [16], with their employee peers from Rivers State in Nigeria postulating for integrative (problem-solving) as secondly used resolution strategy, accordingly [18].

\section{Methodology}

The following section describes the study design employed and the empirical findings' analysis performed, as described next.

\subsection{Study design}

The negotiation and conflict resolution questionnaire was completed by 116 private college students during the academic years 2019/2020 at their institution. They were first asked to fill in demographic information regarding gender, residency state/region, age range, work status (public vs. private) and enrolment to vote questions. Subsequently, they completed the Five Factor Negotiation Scale (FFNS) [9]. The corresponding instrument addressed the following scales: a) selfconfidence (i.e. assessing students' confidence in their self required to be an assertive negotiator (10 questions), b) cooperation (i.e. evaluating participants' willingness to cooperate or work together with others) (8 items), c) communication (i.e. appraising students' willingness to cooperate or work together with others) (9 items), d) compromise/bargaining (i.e. measuring respondents' disposition to give something up, make exchanges and address others' needs in order to achieve their goals), with all of them indicating a 5-point Likert type answering format pending on how often the corresponding statements apply to the respondents $(1=$ never to $5=$ always $)$ and finally, e) conflict resolution (i.e. inclination to talk out to resolve a challenge, disagreement or problem rather than fighting in the face of conflict). This scale included 6 items referring to the type of relationship involved (i.e. parents/guardian, teachers, friends, sisters/brothers, people of same age who are not friends, partner). For each of the above questions, respondents were presented with 5 answer choices, from which they were asked to rank their top 3 on how they handle challenges, disagreements, problems and (or) conflicts (i.e. physical fight, argument/verbal fight, walk away/neutral, get an adult/constructive and talk it out/negotiation). Selfconfidence and communication scales were not included in the analyses performed due to lower reliability. Questions that were negatively worded for presentation were reverse coded before analyses were executed.

\subsection{Data analysis and results}

The data analysis and results show that 89 male and 27 female private university students $(\mathrm{N}=116)$ provided fully completed negotiation-related and conflict resolution instruments overall, representing $76.7 \%$ and $23.3 \%$ of the total respondents' sample, respectively. Most participants originated from Athens state/region region $(\mathrm{N}=62)(53.4 \%)$ in comparison to other state/region origin $(\mathrm{N}=54)$ (46.6 $\%)$ and characterized by a non working $(\mathrm{N}=84)$ $(72.4 \%)$ in relation to working status $(\mathrm{N}=32)$ $(27.6 \%)$. To examine potential differences in the experience of negotiation-associated and conflict resolution continuum strategies used by the respondents, a 2 (state/region origin: Athens vs. other) x 2 (working status: yes vs. no) between groups ANOVAs were performed, as indicated in Tables 1 and 2, below.

3.2.1. $2 \times 2$ ANOVAs. Table 1 illustrates the relevant descriptive statistics that correspond to higher education students' responses to each one of the negotiation-based attitudes assessed by state/region (i.e. Athens, other) and work status (i.e. working, non working), where Table 2 indicates the main and interaction effects for state/region origin (Athens, other) and work status (working, non working) for each of the aforementioned negotiation continuum and conflict resolution-related attitudes measured within private university context.

\section{Cooperation}

Tables 1 and 2 above indicate that was a nonsignificant main effect of state/region on students' willingness to cooperate or work together, $\mathrm{F}(1,116)$ $=0.304, \mathrm{p}=.582$, partial $\eta^{2}=.003$, which means that Athens and other origin students scored similarly in their disposition to cooperate or work together $(\mathrm{M}=3.16$ and $\mathrm{M}=3.09$, respectively). 


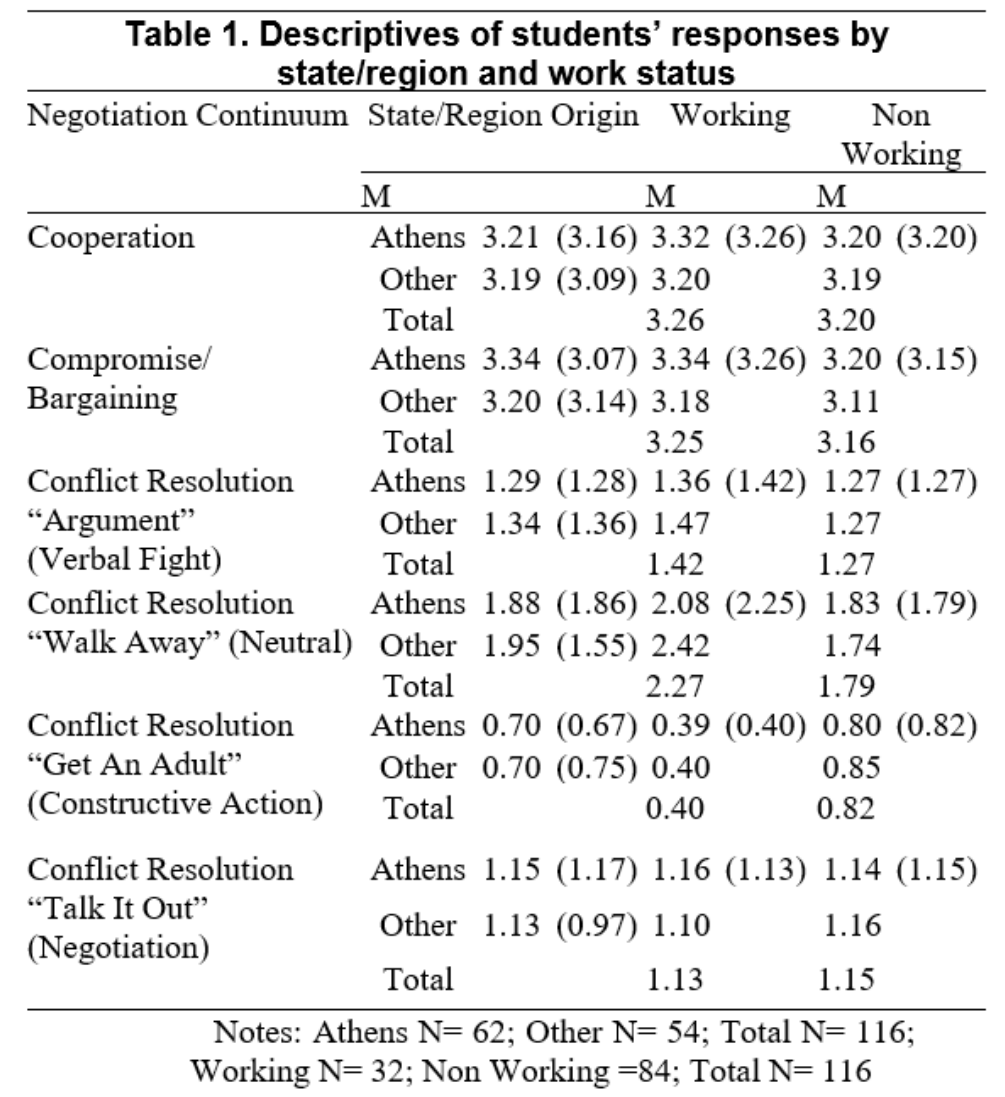

Table 2. Main effects and interaction effect of work status and state/region origin on students' responses

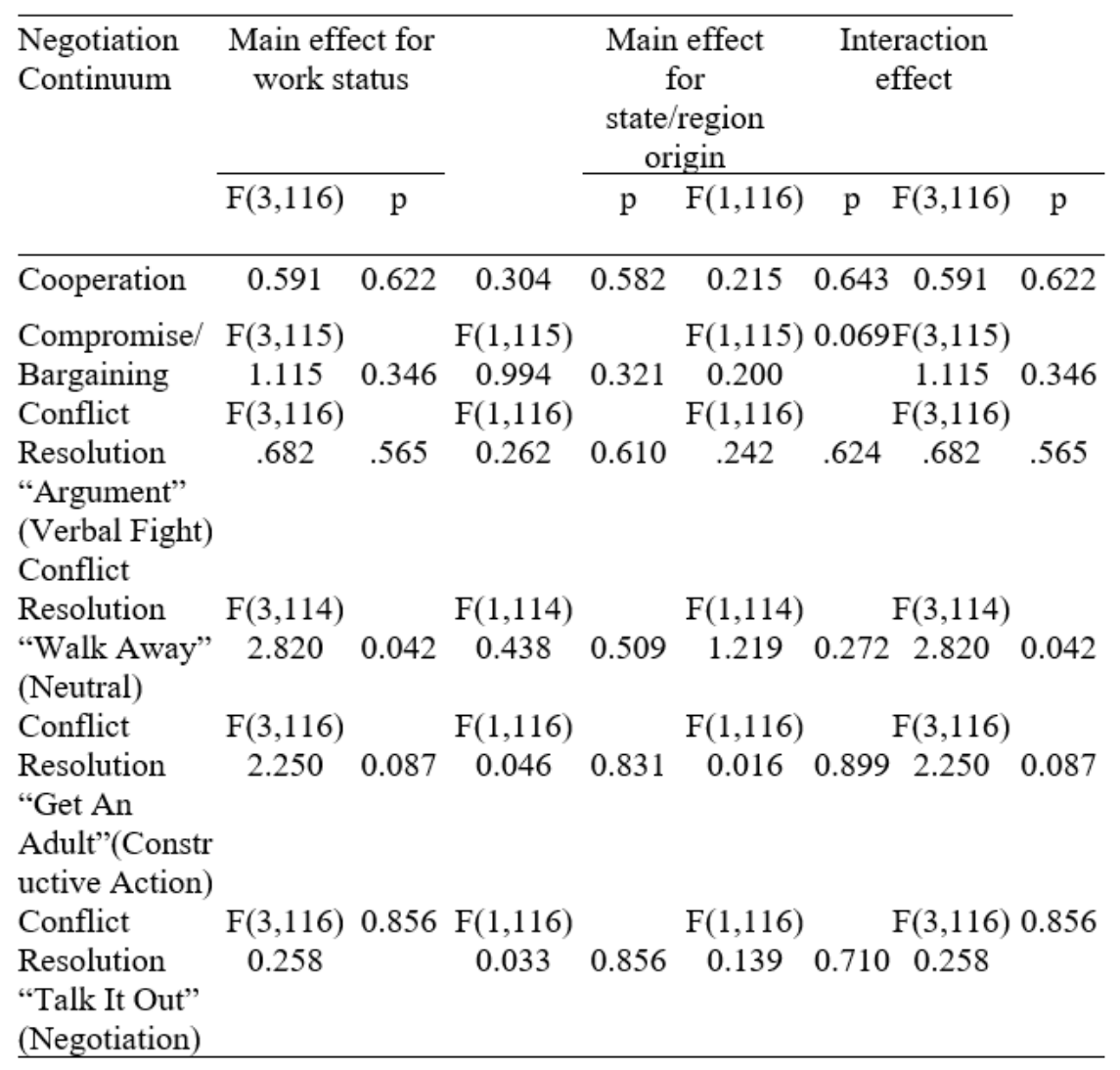


There was a non-significant main effect of work status on students' willingness towards working things out with their co-workers, $\mathrm{F}(3,116)=0.591, \mathrm{p}$ $=.622$, partial $\eta^{2}=.016$, which means that working and non working university students did demonstrate similar scores in their perceptions of cooperation and working together on group projects $(M=3.26$ and $\mathrm{M}=3.20$, accordingly). There was a non-significant interaction effect between municipality and work status on students' cooperation scores, $\mathrm{F}(1,116)=$ $0.215, p=.643$, partial $\eta^{2}=.002$. This indicates that private university students reflecting Athens and other state/region origin both working and non working peers were not affected differently in the perception of cooperation or working things out with others $(M=3.21$ and $M=3.19$ as well as $M=3.26$ and $\mathrm{M}=3.20$, respectively).

\section{Compromise/Bargaining}

Tables 1 and 2 demonstrate that there was a nonsignificant main effect of state/region on students' willingness to give something up, make exchanges and address each other's needs to achieve one's goals, $\mathrm{F}(1,115)=0.994, \mathrm{p}=.321$, partial $\eta^{2}=.009$, which means that Athens and other origin students scored similarly in their disposition to compromise/bargain $(\mathrm{M}=3.07$ and $\mathrm{M}=3.14$, respectively). There was a non-significant main effect of work status on students' compromise/bargaining scores, $\mathrm{F}(3,115)=1.115$, $\mathrm{p}=.346$, partial $\eta^{2}=.030$, which means that working and non working students scored similarly in their willingness to compromise/bargain $(M=3.26$ and $\mathrm{M}=3.15$, accordingly). There was a non-significant interaction effect between state/region origin and work status on students' disposition to give something up, make exchanges and consider each other's needs to accomplish one's goals scores, $\mathrm{F}(1$, $115)=.200, \mathrm{p}=.069$, partial $\eta^{2}=.001$. This indicates that Athens and other origin both working and non working ones were not affected differently in the perception of compromise/bargaining willingness $(\mathrm{M}=3.21$ and $\mathrm{M}=3.13$, as well as $\mathrm{M}=3.25$ and $\mathrm{M}=$ 3.16 , accordingly).

\section{Conflict resolution "argument" (verbal fight)}

Tables 1 and 2 show that there was a nonsignificant main effect of state/region origin on students' conflict resolution "argument" (verbal fight) attitude post-assessment, $\mathrm{F}(1,116)=0.262$, $\mathrm{p}=$ .610 , partial $\eta^{2}=.002$, which means that Athens and other origin students scored similarly in their attitude towards verbal fight $(\mathrm{M}=1.28$ and $\mathrm{M}=1.36$, respectively). There was a non-significant main effect of work status on students' conflict resolution "argument" (verbal fight) attitude scores, F(3,116) $=.682, p=.565$, partial $\eta^{2}=.018$, which means that working and non working students scored similarly in their verbal fight disposition $(\mathrm{M}=1.42$ and $\mathrm{M}=$ 1.27, respectively). There was a non-significant interaction effect between state/region origin and work status on respondents' conflict resolution "argument" (verbal fight) scores, $\mathrm{F}(1,116)=.242$, $\mathrm{p}=.624$, partial $\eta^{2}=.002$. This indicates that Athens and other origin working and non working students were not influenced differently in the perception of conflict resolution "argument", respectively (verbal fight) attitude ( $M=1.29$ and $M=1.34$ as well as $M=$ 1.42 and $\mathrm{M}=1.27$, accordingly).

\section{Conflict resolution "walk away" (neutral)}

Tables 1 and 2 indicate that there was a non significant main effect of state/region origin on participants" "walk away" (neutral) attitude postassessment, $\mathrm{F}(1,114)=0.438, \mathrm{p}=.509$, partial $\eta^{2}=.004$, which means that Athens and other origin students scored similarly in "walk away" perceptions ( $M=1.86$ and $M=1.55$, accordingly) during postnegotiation continuum assessment. There was a significant main effect of work status on students' "walk away" scores, $\mathrm{F}(3,114)=2.820, \mathrm{p}=<.05$, partial $\eta^{2}=.073$, which means that working participants scored significantly higher in "walk away" perceptions $(M=2.25)$ than their non working peers $(\mathrm{M}=1.79)$ post-negotiation continuum. There was a non-significant interaction effect between state/region origin and work status on students' "walk away" perceptions after measurement, $\mathrm{F}(1,114)=1.219, \quad \mathrm{p}=.272$, partial $\eta^{2}=.011$. This indicates that Athens and other origin both working and non working counterparts were not influenced differently in the perception of "walk away" (neutral) negotiation-based behaviour $(\mathrm{M}=1.88$ and $\mathrm{M}=1.95$ as well as $\mathrm{M}=2.27$ and $\mathrm{M}=1.79$, accordingly).

Conflict resolution "get an adult" (constructive action)

Tables 1 and 2 illustrate that there was a non significant main effect of state/region origin on students' "get an adult" attitude, F $(1,116)=0.046$, $\mathrm{p}=.831$, partial $\eta^{2}=.000$, which means that Athens and other origin participants scored similarly in their "get an adult" (constructive action) perceptions $(\mathrm{M}=0.67$ and $\mathrm{M}=0.75$, respectively) post-assessment. There was a non-significant main effect of work status on students' "get an adult" scores, $F(3,116)=$ $2.250, \mathrm{p}=.087$, partial $\eta^{2}=.058$, which means that working and non working counterparts scored similarly in their constructive action disposition ( $\mathrm{M}=$ 0.40 and $\mathrm{M}=0.82$, respectively). There was a non- 
significant interaction effect between origin and work status on students" "get an adult" scores, $\mathrm{F}(1,116)=0.016, \mathrm{p}=.899$, partial $\eta^{2}=.000$. This indicates that Athens and other origin both working and non working peers were not affected differently in their perceptions of "get an adult" (constructive action) choice $(\mathrm{M}=0.70$ and $\mathrm{M}=0.70$ as well as $\mathrm{M}=$ 0.40 and $\mathrm{M}=0.82$, accordingly).

\section{Conflict resolution "talk it out" (negotiation)}

Tables 1 and 2 demonstrate that there was a nonsignificant main effect of state/region origin on students' "talk it out" (negotiation) attitude, F $(1,116)=0.033, \mathrm{p}=.856$, partial $\eta^{2}=.000$, which means Athens and other origin students scored similarly in their "talk it out" (negotiation) attitude $(\mathrm{M}=1.17$ and $\mathrm{M}=0.97$, respectively). There was a non-significant main effect of work status on respondents' "talk it out" scores, $\mathrm{F}(3,116)=0.258$, $\mathrm{p}=.856$, partial $\eta^{2}=.007$, which means that working and non working counterparts scored similarly in their "talk it out" choice $(\mathrm{M}=1.13$ and $\mathrm{M}=1.15$, respectively). There was a non-significant interaction effect between state/region origin and work status on students' "talk it out" (negotiation) scores, $\mathrm{F}(1,116)=0.139, \quad \mathrm{p}=.710$, partial $\eta^{2}=.001$. This indicates that Athens and other origin both working and non working counterparts were not affected differently in their perceptions of "talk it out" (negotiation) choice during their assessment (M= 1.15 and $\mathrm{M}=1.13$ as well as $\mathrm{M}=1.13$ and $\mathrm{M}=1.15$, accordingly).

\section{Discussion}

The findings illustrated in the present paper seem not only to lend support but also to contrast analogous ones in previous higher education and (or) workplace negotiation and conflict resolution attitudes alike. Overall, they tend to corroborate prior evidence indicating state (region) origin effect in the practice of certain negotiation continuum and conflict resolution strategies [17], as a) current students did exhibit willingness to work together (cooperation), inclination to give something up, make exchanges and address each other's needs to accomplish one's goals (compromise/bargaining), supplemented by b) the fundamental 3 choices of dealing with disagreements, issues or conflicts using argument (verbal fight), walk away (neutral), get an adult (constructive action) and talk it out (negotiation), regardless of their state (region) origin. This might be conducive either to the private higher education institution's conflict resolution culture aspects existed which may foster negotiation approach practice to students or to conflict resolution fusion initiated by the corresponding respondents based on the kind of explored relationships involved
[16]. Complementary to our evidence, diverse course university students from North Cyprus and South Eastern USA public university appeared to strongly agree with compromise/bargaining and avoidance strategy the most [as above], with their employee counterparts from Rivers State in Nigeria scoring higher in integrative (problem-solving), as second higher scoring resolution approach, accordingly [18]. However, they tend to contradict previous ones that report working individuals scoring higher in constructive-oriented (problem-solving) conflict resolution attitude and not "walk away" strategy like indicated in our academic context [as above]. Such negotiation continuum and conflict resolution strategies chosen may be attributed to particular culture aspects and working students' "professional norms" [21 p. 452 cited in 19 p. 1164] present within their workplace settings that may support or hinder certain negotiation and conflict management perceptions and skills by matching employees [22].

\section{Conclusion}

The present study aimed to follow research calls for additional exploration of negotiation continuum and conflict resolution strategies within different academic and workplace context [23]. By exploring negotiation and conflict management attitudes and skills instigated by private university students in Greece and addressing the issue of potential state (region) and work status differences across and within the corresponding strategies employed. Along this vein of investigation, it might worth expanding current research and related negotiation and conflict resolution strategies paradigms by exploring further human personality characteristics to negotiation and conflict management attitudes in local, national and cross-cultural settings, comparing evidence of academic with business contexts and working individual responses, as well. Following current advanced solutions negotiation-instruction research (e.g. intelligent tutoring systems, multimodal ECAs, robots, etc.) and connecting it with corresponding affective computing personality studies [24], it might be also interesting to explore agents' personalities in delivering effective human negotiation and conflictresolution behavioural change, cross-culturally.

\section{References}

[1] Mahmoodi, K. (2012) "Negotiation strategies and skills in international business. A study of negotiators in Finland" Bachelor's degree thesis in Business Administration Specialiation in International Business Management Turku University of Applied Sciences, Finland pp. 1-79.

[2] Roll, I., Aleven, V., McLaren, B.M. and Koedinger, K.R. (2011) "Metacognitive practice makes perfect: 
Improving students' self-assessment skills with an intelligent tutoring system" In Biswas et al. (Eds.) AIED 2011, LNAI 6738, pp. 288-295.

[3] Gama S., Barata G., Gonşalves D., Prada R. and Paiva A. (2011) "SARA: social affective relational agent: a study on the role of empathy in artificial social agents" In: D’Mello S., Graesser A., Schuller B., Martin J.C. (Eds.) Affective computing and intelligent interaction, ACII 2011 Lecture Notes in Computer Science, vol. 6974 Springer, Berlin, Heidelberg, pp 507-516.

[4] Robbins, S.P. and Judge, T.A. (2013) "Organizational Behavior" $15^{\text {th }}$ Edition. Pearson.

[5] Kinicki, A. and Kreithner, R. (2008) "Organizational Behaviour: Key Concepts, Skills and Best Practice". New York: The McGraw-Hill Companies.

[6] Lewicki, R.J., Hiam, A. and Olander, K.W. (1996) "Think Before You Speak: A Complete Guide to Strategic Negotiation”. Wiley.

[7] Hochhauser, M., Weiss, P. L. and Gal, E. (2018) "Enhancing conflict negotiation strategies of adolescents with autism spectrum disorder using video modeling", Assistive Technology, 30 (3), pp. 107-118.

[8] Nikopoulos, C.K. and Keenan, M. (2004) "Effects of video modeling on social initiations by children with autism", Journal of Applied Behavior Analysis, 37 (1), pp. 93-96.

[9] Nakkula, M.J. and Nikitopoulos, C.E. (2001) "Negotiation training and interpersonal development: an exploratory study of early adolescents in Argentina", Adolescence, 36, Spring, 141, pp. 1-20.

[10] Laursen, B., Hartup, W.W. and Koplas, A.I. (1996) "Towards understanding peer conflict", Merill-Palmer Quarterly, 42, pp. 76-102.

[11] Brett, J. M. (2014) "Negotiating globally: How to negotiate deals, resolve disputes and make decisions across cultural boundaries". 3rd Edition. San Francisco: Jossey-Bass.

[12] Lewicki, R. J. and Stark, N. (1996) "What is ethically appropriate in negotiations: An empirical examination of bargaining tactics", Social Justice Research, 9, pp. 69-95.

[13] Park, H. and Antonioni, D. (2007) "Personality, reciprocity, and strength of conflict resolution strategy", Journal of Research in Personality, 41, pp. 110-125.

[14] Ford-Wood, V. and Bell, P.A. (2008) "Predicting interpersonal conflict resolution styles from personality characteristics", Personality and Individual Differences, 45 , pp. 126-131.
[15] Schneer, J.A. and Chanin, M.A. (1987) "Manifest needs as personality predispositions to conflict-handling behavior”, Human Relations, 40 (9), pp. 575-590.

[16] Kiralp, Y., Dincyürek, S. and Beidoğlu, M. (2009) "Determining the conflict resolution strategies of university students", Procedia Social and Behavioral Sciences, 1, pp. 1205-1214.

[17] Dinçyürek, S. (2003) "Üniversite Öğrencilerinin Kullandiklari Çatişma Çözümleme Stratejilerinin Berirlenmesi, Lefkoşa (Yayinlanmamiş Yüksek Lisans Tezi, Yakin Doğu Teknik Üniversitesi).

[18] Dialoke, I. and Ogbu, E.F. (2017) "Conflict Resolution Strategies and Workers' Commitment in Selected Oil Companies in Rivers State", International Journal of Business Ethics in Developing Economies, 6 (2), December, pp. 1-10.

[19] Bouwman, R., van Thiel, S., van Deemen, A. and Rouwette, E. (2019) "Cooperation and Competition in Public-Sector. Negotiations: A Laboratory Experiment", Public Performance and Management Review, 42 (5), pp. 1164-1185.

[20] Taylor, K. A., Mesmer-Magnus, J. and Burns, T.M. (2008) "Teaching the Art of Negotiation: Improving Students' Negotiating Confidence and Perceptions of Effectiveness", Journal of Education for Business. Heldref Publications, January/February, pp. 135-140.

[21] Lewicki, R. J., Saunders, D. M. and Barry, B. (2015) "Negotiation (7th ed.). New York: McGraw-Hill.

[22] Makri, E. (2008) "Sociopsychological processes and their effects on M and As", Doctoral dissertation. Panteion University of Social and Political Sciences. Athens, Greece.

[23] Rahim, M.A. and Katz, J.P. (2020) "Forty years of conflict: the effects of gender and generation on conflictmanagement strategies", International Journal of Conflict Management, 31 (1), pp. 1-16.

[24] Lee, S., Lee, G., S. Kim, S. and Lee, J. (2019) "Expressing personalities of conversational agents through visual and verbal feedback", Electronics, 8 (7), 794

\section{Acknowledgements}

The author thankfully declares the support provided by the educational institution and the time and effort that participating students allocated in making this study possible. 